\title{
Which way to the wheat field? Women of the radical right on Facebook
}

\author{
Megan Squire \\ Elon University \\ msquire@elon.edu
}

\begin{abstract}
At what rates and in what capacity do women participate in extreme far-right ("radical right") political online communities? Gathering precise demographic details about members of extremist groups in the United States is difficult because of a lack of data. The purpose of this research is to collect and analyze data to help explain radical right participation by gender on social media. We used the public Facebook Graph API to create a large dataset of 700,204 members of 1,870 Facebook groups spanning 10 different far-right ideologies during the time period June 2017 - March 2018, then applied two different gender resolution software packages to infer the gender of all users by name. Results show that users inferred to be women join groups in some ideologies at a greater rate than others, but ideology alone does not determine leadership opportunities for women in these groups. Furthermore, our analysis finds similarities between historical women's organizations such as the 1920s Women's Ku Klux Klan and contemporary online "wheat field" groups designed specifically for women.
\end{abstract}

\section{Introduction}

2017 was a very active year for radical right extremist political groups in the United States. Press coverage of the far-right became a regular occurrence as new "Alt-Right" groups combined with white nationalists, militias, neo-Confederates, nativists, and others to stage public rallies around a variety of causes, including anti-immigration and anti-Muslim positions, protests against removal of Confederate monuments, pro-Second Amendment events, and so on. Images of young white men marching with torches and chanting "Blood and soil!" predominated news coverage, and evidence of women in this movement was scant.

Indeed, quantitative data on the gender demographics of the modern radical right in the United States is nearly non-existent. In the wake of the deadly Unite the Right rally in Charlottesville, Virginia, the popular press reported the estimate of one expert that $20 \%$ of the alt-right might be female [1]. The Anti-
Defamation League (ADL) used video evidence to conclude that "alt-right is overwhelmingly white and male" as only 7\% of the Unite the Right attendees they could identify appeared to be women [2]. Before Charlottesville, a 2016 psychological study by Forcher and Kteiley [3] of self-identified alt-right adherents yielded a sample that was $34 \%$ female. Even earlier, a 2010 Quinnipiac University poll of the Tea Party movement (some of which subsequently morphed into the anti-government "patriot" militia movement of today [4]), showed that women make up $55 \%$ of selfidentified Tea Party members [5]. Clearly, more reliable estimates of gender breakdown are needed.

Kathleen Blee, who writes extensively about women in clandestine white power groups in the United States, including neo-Nazis, racist skinheads, and the Ku Klux Klan, explained this paucity of data in 2002: "A statistically random sample of racist activists is not possible because there is no comprehensive list of racist activists or even a reliable estimate of their numbers. Except for a few public leaders, most racist activists are interested in keeping themselves hidden from the public, and the scholarly, eye." [6]

Thus, the purpose of our study is to extend existing scholarship by collecting much-needed data about the gender demographics of the contemporary radical right, especially in terms of how the movement exists on social media. The main contributions of this work are:

- We find that users inferred to be women join Facebook groups in some ideologies at a greater rate than other groups and other ideologies.

- Our analysis also shows that some ideologies create groups especially for women (which they mockingly call "wheat fields", explained more in Section 3.1.1), and in most cases these women's groups are effective at attracting female participation and leadership.

- We describe similarities between these contemporary radical right "wheat fields" and historical women's auxiliaries such as those created by the 1920s Ku Klux Klan.

In Section 2, we present our Facebook data set, including the process we used to collect and store it, and 
our classification of groups and events into ideologically distinct divisions. In Section 3 we describe our method for resolving the likely gender of Facebook user accounts, we present our analysis of gender by ideology and group, and we compare our findings to previous scholarship on similar historical women's groups. Section 4 reviews the limitations of our approach and suggests avenues for future work with this data, and in Section 5 we review our findings and conclusions.

\section{Facebook data set}

To build our data set, we located 1,843 Facebook groups and 27 events from 10 different far-right ideologies that were politically active in the United States during the period June 2017 - March 2018. We relied on descriptions of each far-right ideology from two US-based not-for-profit extremist monitoring groups: The Southern Poverty Law Center (SPLC) and The Anti-Defamation League (ADL).

\subsection{Far-right extremist ideologies}

Here we provide brief descriptions of each ideology, and the keywords and personalities associated with this ideology. (Next to each ideology we also provide the abbreviation we use for it in tables later in this paper.)

Alt-Right (AR). This is an umbrella term used to describe groups who believe that European heritage and white identity and civilization are under attack by "political correctness" and "social justice warriors." These groups have a strong online tradition in gaming communities and in the production of memes. Key concepts: Identity Evropa, Kekistan, Pepe the frog, antiSJW, identitarianism, Tradwives, memes, Richard Spencer, Augustus Sol Invictus, Christopher Cantwell, Mike Enoch/Peinovich, Andrew Anglin. [7, 8]

Anti-Government/"Patriot"/Militia

(AGM). Militias are non-professional armies. Right-wing antigovernment groups promote conspiracy theories involving perceived government overreach that can only be kept in check by a citizen-led militia movement. Concepts include: New World Order, FEMA concentration camps, The Turner Diaries, extreme traditional constitutionalism, doomsday "prepping", Oath Keepers, Three Percenters, 3\% / III\%. [9, 10, 11]

Anti-Immigrant (AI). These groups oppose immigration into the United States as well as the immigrants themselves. Some believe there exists a government conspiracy to unify Mexico and the United States in a "North American Union". Key concepts: Center for Immigration Studies, ALIPAC, Federation for American Immigration Reform (FAIR), nativism, border patrols, David Horowitz, Glen Spencer. [12, 13]
Anti-Muslim (AM). Anti-Muslim groups oppose the religion of Islam and are hostile to its adherents. Key groups and concepts include: ACT 4 America / ACT!, American Infidels, Bikers Against Radical Islam, creeping Sharia, Islamization of America, Brigitte Gabriel. [14, 15]

Anti-Semitic (AS). These groups are hostile to the Jewish religion and promote hatred based on the perceived inferiority of Jewish people. Key concepts include: Holocaust denial, the "Jewish Question" ("JQ"), Goyim, Zionist Occupied Government (ZOG), Anti-Jewish, (((echo parentheses))), Christian Identity, True Israelites, Adamites, Dual-Seedline. [16, 17, 18]

Manosphere (MN). The "manosphere" is a collection of groups and online sites advocating male supremacy and subjugation of women. Key concepts: Men Going Their Own Way (MGTOW), incel (involuntarily celibate), False Rape Society, pickup artists, anti-feminism, men's rights activists, Milo Yiannopoulos, Roosh V., Mike Cernovich. [19, 20]

Neo-Confederate (NC). Neo-Confederate groups advocate secession from the United States, the creation of a separate state based in the American South, reverence for and valorization of Southern historical revisionism and symbols from the Civil War era such as the Confederate Flag. [21, 22]

Neo-Nazi (NN). These groups idolize Adolf Hitler and want to recreate a fascist political state reminiscent of Nazi Germany. Keywords include: National Socialism, The Daily Stormer, Creativity Movement, American Nazi Party, American Blackshirts, Traditionalist Workers Party, TradYouth, Esoteric Hitlerism, National Alliance, Aryan Nations, Vanguard America, Michael Heimbach, Jeff Schoep. [23, 24]

Proud Boys/Alt-Knights (PB). Proud Boys comprise what they call a "western chauvinist fraternity." The Alt-Knights are fashioned to be its militant fighting arm. Key concepts and personalities include: Western Chauvinism, Based Stickman, Kyle Chapman, Gavin McInnes, FOAK (Fraternal Order of Alt-Knights), Proud of your boy, Uhuru. [8, 25, 26, 27]

White Power (WN). White power groups promote white supremacist, white separatist, or white nationalist ideologies. Key concepts include white European ethnonationalism, identitarianism, race "realism", white power, white pride, RaHoWa ("racial holy war"), racist Asatru/folkish beliefs, skinhead culture, Ku Klux Klan. $[28,29,30]$

\subsection{Finding and classifying groups and events}

The primary ideology for each group or event was determined by visually inspecting its name, its description, its cover photo, its content (for Public groups), its linked Pages, and its stated affiliation with 
extremist groups. Two independent panels of subject matter experts (one from an extremist monitoring organization and one from a community watchdog group) were convened to assist in constructing the ideological categories and classifying groups.

Five methods were used to find the groups and events: (1) keyword searching within Facebook; (2) automated keyword searching using the Facebook Search API; (3) using the "Suggested Groups" provided by Facebook; (4) browsing the visible group lists attached to the timelines of heavy users within each ideology; and (5) using the "Linked Groups" feature provided by some Facebook Pages.

Because our ideological classifications are USspecific, we only collected groups and events for which the name and description were in the English language, and we avoided collecting groups that were clearly designed to represent users from non-US regions.

\subsection{Group membership roster collection}

Once we had the groups identified and assigned to a primary ideology, we wrote software to access the Facebook Graph API version 2.10 to collect group and event membership rosters. The membership rosters for both Public and Closed groups and Public events were publicly viewable in any browser or via the Facebook app [31, 32] at this time. Until April 4, 2018 these were also available via the Facebook developer API to anyone with a valid authentication token [33]. At that time, the API yielded the list of current members for any Public or Closed group or event, including the user's display name and a unique user identification number called the app_scoped_user_id (ASID), as well as the user's role within that group (member, administrator, and so on). Because users have the same ASID across all groups and events, it was possible to observe the same user joining multiple groups or events.

We collected group names, descriptions, and membership lists only from Public and Closed groups [31]. (As of June 2018, membership lists are no longer published for Closed groups.) We followed a similar procedure for events, only collecting information from Public events with visible guest lists [32], and we only collected respondents who had proactively indicated they were either "Going" or "Interested". We did not join any event guest lists ourselves, and we did not collect any lists of "Invited" but non-responsive participants. For the rest of this paper, the generic term "group" will refer to both groups and events.

In constructing this data set, we followed Facebook's data collection policy, including using the Developer API and otherwise abiding by its Terms of Service and Platform Policy for data use [34]. Additionally, our app did not request or receive any private information from users themselves; we only asked Facebook itself via its API for membership rosters which were already publicly viewable. After the data was collected from Facebook, it was stored in a MySQL database.

Table 1 shows the relative sizes for all ten ideologies in the database. "Total Unique Members" refers to the number of members that joined the groups in a given ideology. Because users can join groups in multiple ideologies, the sum of this column will exceed the 700,204 unique users in our database.

Table 1. Far-right Facebook Groups/Events, divided by Primary Ideology

\begin{tabular}{|l|r|r|r|r|}
\hline Ideology & \multicolumn{1}{|}{$\begin{array}{c}\text { M } \\
\text { Groups }\end{array}$} & $\begin{array}{c}\text { Total } \\
\text { Users }\end{array}$ & $\begin{array}{c}\text { Max } \\
\text { Group } \\
\text { Size }\end{array}$ & $\begin{array}{c}\text { Mean } \\
\text { Group } \\
\text { Size }\end{array}$ \\
\hline NC & 453 & 182,621 & 19,447 & 662 \\
\hline WN & 379 & 73,582 & 14,712 & 233 \\
\hline AGM & 273 & 101,211 & 11,509 & 473 \\
\hline AR & 246 & 99,996 & 36,666 & 587 \\
\hline PB & 157 & 7,920 & 1,348 & 72 \\
\hline AM & 136 & 128,467 & 17,824 & 1,270 \\
\hline MN & 82 & 36,435 & 8,658 & 643 \\
\hline AI & 51 & 115,511 & 51,117 & 2,823 \\
\hline NN & 48 & 6,218 & 1,251 & 139 \\
\hline AS & 45 & 16,498 & 9,310 & 400 \\
\hline
\end{tabular}

\section{Gender resolution and data analysis}

This section describes how gender was inferred from first names, then presents a subsequent analysis of gender participation by ideology and in groups.

\subsection{Gender resolution by name}

In many cultures it is possible to infer gender from a person's first name. Gender resolution software attempts to predict a gender for a name within a given cultural or geographic area by using pre-built "name lists" that assign a probability for each gender and each name. Most name-based gender predictors also provide a way to handle androgynous or unknown names. While no automated or software-based method will be as accurate a predictor as simply asking a person what gender they identify with, gender resolution software is at least a starting point when the amount of data is large or when we lack contact information.

Two gender resolution packages with libraries for Python were used for this project: gender-guesser [35] and the Genderize.io API [36]. The first package, gender-guesser, uses a large list of known names in five categories: male, mostly male, female, mostly female, androgynous, or unknown. The second system, Genderize.io, also uses a list of names, but its database is based on the genders assigned to first names on social 
media accounts: male, female, or unknown. We wrote software to use each of these packages to guess the gender of each of the 62,792 distinct first names in the data set. Table 2 shows the results.

Table 2. Results of gender resolution process

\begin{tabular}{|l|r|r|r|r|}
\hline \multirow{2}{*}{} & \multicolumn{2}{|c|}{ Gender-Guesser } & \multicolumn{2}{c|}{ Genderize.io } \\
\cline { 2 - 5 } & \multicolumn{1}{c|}{$\#$} & \multicolumn{1}{c|}{$\%$} & \multicolumn{1}{c|}{$\%$} & \multicolumn{1}{c|}{$\%$} \\
\hline Female/mostly female & 176,829 & $25 \%$ & 198,116 & $28 \%$ \\
\hline Male/mostly male & 435,023 & $62 \%$ & 465,851 & $66 \%$ \\
\hline Androgynous & 6,924 & $1 \%$ & - & - \\
\hline Unknown & 83,384 & $12 \%$ & 38,193 & $5 \%$ \\
\hline
\end{tabular}

To test the accuracy of the predictions, the softwaregenerated gender guesses were compared to a preclassified set of 1,855 users whose gender was specified by them in their Facebook public profile. Table 3 summarizes the results of the error estimation task.

Table 3. Error estimation for gender guessers

\begin{tabular}{|l|r|c|r|r|}
\hline \multirow{2}{*}{} & \multicolumn{2}{|c|}{ Gender-Guesser } & \multicolumn{2}{c|}{ Genderize.io } \\
\cline { 2 - 5 } & $\#$ & $\%$ & \multicolumn{1}{c|}{$\#$} & \multicolumn{1}{c|}{$\%$} \\
\hline Correct & 1611 & $86.8 \%$ & 1711 & $92.2 \%$ \\
\hline Incorrect & 244 & $13.2 \%$ & 144 & $7.8 \%$ \\
\hline
\end{tabular}

Tables 2 and 3 indicate that Genderize.io yields fewer unknowns (5\% vs 12\%) and fewer errors $(7.8 \%$ vs $13.2 \%$ ). Therefore, for the remainder of our analysis, we will use genders inferred by Genderize.io.

With respect to the goal of measuring female participation in the radical right, both gender resolution packages yield figures ( $25 \%$ and $28 \%$ respectively) that are right in the middle of the scant prior estimates presented in Section 1 (recall these were 20\%, 7\%, 34\%, and 55\%). Automated gender inference is imprecise and occasionally unsatisfying, but even taking a maximum error rate into account, the figures are still believable given prior estimates.

From this point forward in this paper, when the terms "women" or "female" are used to refer to Facebook users, this can be considered a shorthand for "Facebook users who were inferred to be female by Genderize.io."

\subsection{Ideological participation by gender}

Are there some radical right ideologies that attract or retain women at a greater rate than others? Table 4 shows summary statistics for each inferred gender (male, female, unknown) as resolved by Genderize.io. These are sorted high-to-low by the proportion of female users participating in that ideology.

Anti-Immigrant, Neo-Confederate, and AntiMuslim have the highest female participation rates. Unsurprisingly, the Proud Boys and Manosphere categories have the lowest female participation rates.
Table 4. Ideological participation by inferred gender

\begin{tabular}{|l|r|r|r|}
\hline Ideology & Female \% & Male \% & Unknown \% \\
\hline AI & 40.6 & 56.2 & 3.2 \\
\hline NC & 30.2 & 66.5 & 3.3 \\
\hline AM & 28.1 & 65.7 & 6.2 \\
\hline WN & 26.9 & 67.7 & 5.4 \\
\hline AGM & 24.1 & 72.8 & 3.1 \\
\hline AS & 22.7 & 66.3 & 11.0 \\
\hline NN & 15.3 & 76.0 & 8.7 \\
\hline AR & 13.8 & 78.3 & 7.9 \\
\hline PB & 11.9 & 84.5 & 3.5 \\
\hline MN & 11.8 & 76.9 & 11.3 \\
\hline
\end{tabular}

3.2.1. Explaining "unknowns". We briefly attempted to find out the reason for the relatively high numbers of "unknown" names found in the Anti-Semitic and Manosphere categories. We tested the frequency of character sets (Cyrillic, Turkish, Hebrew, Arabic, etc.) that were used in the unknown first names from different ideologies. On a percentage basis, we found that character sets alone could not explain the numbers of unknowns in these two ideologies. In fact, other ideologies had more unknown names with non-Latin character sets. Next, we counted the frequency of the specific unknown names, but no clear patterns emerged there either. Across all ideologies, the most common unknown name was "Micheal," presumably a variant of "Michael". In the Manosphere category the secondhighest unknown name was "Mgtow" (short for "Men Going Their Own Way," the name of an online community), but the frequency of this name alone does not explain the $11 \%$ "unknowns" across that ideology. More work should be done to tease out the reason for the high numbers of unknowns in these two categories, but that is beyond the scope of this paper.

\subsection{Group participation by women}

In this section we examine the specific patterns of participation by women in the groups that comprise the ten ideologies in our data set. First, we introduce our terminology to describe online spaces specifically designed for women ("wheat fields"), and then we investigate whether and how these wheat fields exist across the spectrum of radical right groups.

3.3.1. Wheat fields. Stock photographs of white women in fields of grass or wheat have become a popular meme in far-right online communities. This imagery is used to reinforce beliefs about the beauty and superiority of white European culture, inspiring white men to protect an imagined pure white womanhood. White nationalist leader Richard Spencer referenced wheat field imagery in a 2016 speech about his vision for an all-white ethnostate: "We would have passed by 
great forests and beautiful images of blond women in a wheat field with their hands, running them through the wheat. It would be a wonderful sight." [37]

Wheat field imagery has been used as cover art by online groups across multiple ideologies including the official Alt-Right web site, and by former Ku Klux Klan grand Wizard David Duke on Twitter [38]. In the leaked chat logs [39] from the Discord server allegedly used to plan the deadly Unite the Right rally held on August 12, 2017 in Charlottesville, Virginia, female-identified users were placed into a special role and channel called "Wheatfield Dwellers" [sic]. Inspired by this metaphor, we searched for other examples of online "wheat fields" in the Facebook extremist ecosystem.

3.3.2 Ideologies with wheat fields. Our data shows that some ideologies do intentionally create "wheat field" groups that cater to women, and that women do join these wheat fields at higher rates than men. Wheat fields are typically named using overtly gendered language (wives, girls, ladies, daughters, bitches, Eve, and so on), overtly claim to be specifically designed for women, and do have a supermajority of women users.

Figure 1 shows the percentage of female membership ( $\mathrm{Y}$ axis) in every group across the five ideologies (X axis), sorted by percent women, high-tolow. Each graph shows the wheat fields on the left spiking far above the rest of the groups. Table 5 gives additional details about the composition of the five ideologies with wheat fields.

For each ideology, Table 5 shows the maximum percentage of women for any wheat field ("Max WF $\% ")$. Next, we show the percentage of female enrollment in the next-highest non-wheat field group ("Max NWF $\% ")$. Third, we calculate the percentage difference between female participation in those two sets of groups. The higher the difference, the more that ideology appears to isolate women into the wheat fields. Finally, we show the standard deviation for female participation across all groups in the ideology, which indicates how dramatic the difference is between the female participation in wheat fields versus non-wheat fields. What do we know about each of these five ideologies and their wheat fields?

The "Proud Boys" movement was created specifically to promote male supremacy, promises to "venerate the housewife" notwithstanding [40]. The AltKnights were created as a militant wing of the Proud Boys, but Alt-Knights do not necessarily follow the same specific rules about gender exclusivity [41]. Our data shows that out of 157 Proud Boys and Alt-Knights groups in our data set, only two of them have femaleinferred participation rates above $25 \%$. These groups both are fan clubs specifically designated for "Girls" who want to be affiliated with the Proud Boys. These two groups are comprised of $96 \%$ and $84 \%$ women (total user count 113, and 58, respectively). No other Proud Boys group has female participation above $11 \%$. (That $11 \%$ group did specify "Girls allowed" in its title, but it has been disavowed by the founder because of this [42]. It had 184 members total.) Four Alt-Knight fan clubs dedicated to founder Kyle Chapman, also known as "Based Stickman," had female participation around $25 \%$ (total user counts ranging between 107 and 611).

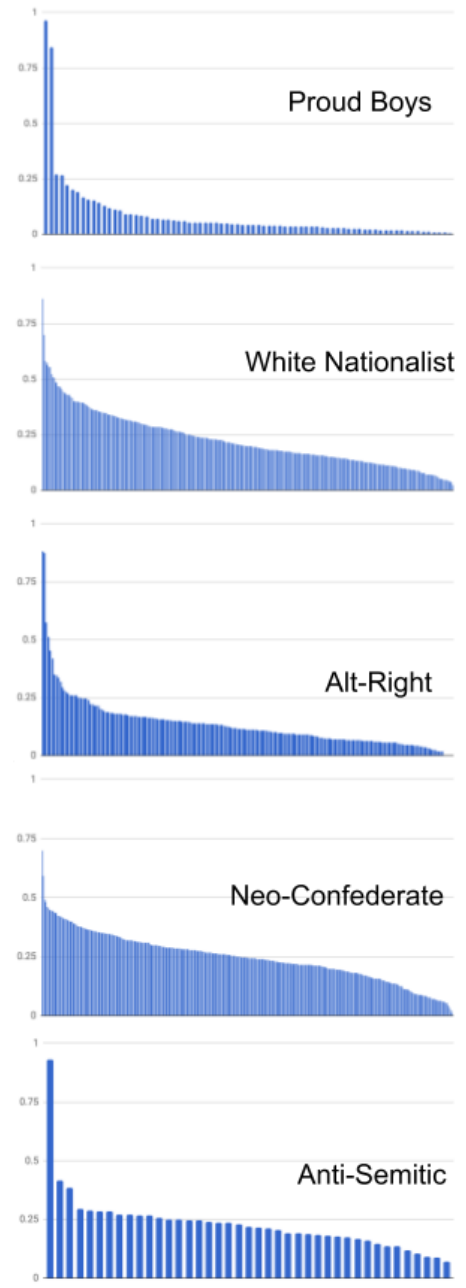

Figure 1. Percent participation by women in groups, divided by ideology. "Wheat field" groups appear on the left side of each graph.

Table 5. Ideologies with wheat fields, sorted by difference in female participation rates in wheat fields (WF) vs. non-wheat fields (NWF)

\begin{tabular}{|l|r|r|r|r|}
\hline Ideology & $\begin{array}{c}\text { Max } \\
\text { WF \% }\end{array}$ & $\begin{array}{c}\text { Max } \\
\text { NWF \% }\end{array}$ & Diff. & Stdev \\
\hline PB & $96 \%$ & $27 \%$ & $69 \%$ & 14.6 \\
\hline AS & $93 \%$ & $42 \%$ & $51 \%$ & 13.4 \\
\hline AR & $88 \%$ & $51 \%$ & $37 \%$ & 11.4 \\
\hline WN & $86 \%$ & $58 \%$ & $28 \%$ & 12.3 \\
\hline NC & $70 \%$ & $59 \%$ & $11 \%$ & 10.2 \\
\hline
\end{tabular}


White Power/White Nationalist group participation by women rarely exceeds $50 \%$. However, two groups specifically designed for women show participation rates of $86 \%$ and $70 \%$ (total user counts of 43 and 327 , respectively). One uses the term "Lupae" in its name, referencing female wolves, and the other is named for the skinhead "bitches" of a certain telephone area code. A third group is affiliated with an official white nationalist women's federation, but this group only has $47 \%$ female participation (286 total users). Two other groups claim to be designed for women, describing themselves as "for red-pilled nationalist and fashy ladies to discuss politics, beliefs, and much more" or "ladies of the of the right wing [sic] persuasion, nationalist and fascist women". These groups only have $30 \%$ and $31 \%$ female participation, however (54 and 119 total users, respectively).

We find that the two Alt-Right groups with the highest participation rates by women ( $88 \%$ each) are both "Tradwives" groups (68 and 117 users total). This term refers to women who embrace a traditional, submissive role as a wife or mother [43]. One group explains its relationship to the male-dominated and meme-hungry Alt-Right as follows: "While our husbands are busy posting dank memes (and supporting our families), we're busy caring for the babes and the household." The next three groups with the highest rates of female participation in the Alt-Right category all have group names and descriptions which explicitly refer to being specifically designed for women and families, but these have only $57 \%, 51 \%$, and $45 \%$ female participation (total user counts: 75, 39, and 11).

The Anti-Semitic ideological category is one of the smaller ones in our data set, and only one group in this category had a name, description and cover photo indicating it was specifically designed for women. With a $93 \%$ female membership from a total user count of 44 , that group has one of the highest percentages in our collection. This group is affiliated with an Anti-Semitic religion called Christian Identity [44]. Aside from this one group, the rest of the Anti-Semitic category is unremarkable, and its level of female participation is uniform. The next-highest non-wheat field group in this category only includes $42 \%$ women (total users, 199).

Finally, we find trace evidence of wheat fields in the Neo-Confederate ideology, with only one group specifically named and designed for women. This group is not very large, nonetheless it has a female participation rate of $70 \%$ (total user count 236). No other Neo-Confederate groups have more than 59\% female members, regardless of whether it was designed to be a wheat field or not. This includes groups which specifically named a female audience along with men, for example "warriors and belles" or "sons and daughters."
3.3.3 Ideologies without wheat fields. Our data shows that there are four ideologies - Anti-Immigrant, Anti-Muslim, Manosphere, and Neo-Nazi - that have no wheat field Facebook groups. Figure 2 (next page) shows each of these four ideologies and the participation rates of women in their groups. In contrast to Figure 1, these four graphs show no large spikes of female participation.
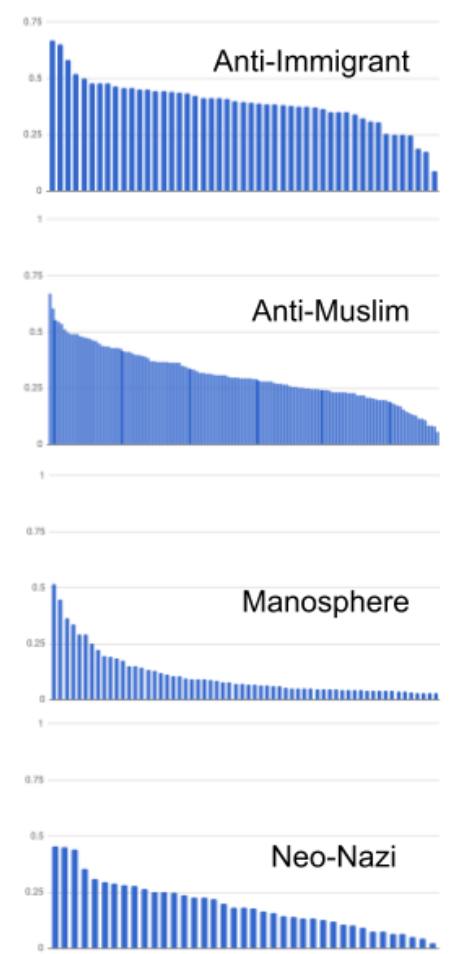

\section{Figure 2. Percent participation by women in far-right groups without women-focused spaces, divided by ideologies.}

Among these four ideologies, the highest participation rates by women are in Anti-Immigrant and Anti-Muslim categories. Themes for these groups are not overtly gender-focused. Rather, they include topics like protesting drunk driving by illegal immigrants, protesting against Sharia law in the U.S., and so on.

In all four of these ideologies, there is only one group claiming to be specifically made for women, however upon a closer read it is revealed to be an outreach effort to recruit women "with a brain" who are against the "Islamic rape epidemic [that has] infested the civilized world." This group has only $41 \%$ female participation (total user count of 765).

Neo-Nazi and Manosphere groups have very low levels of participation by women overall, and they also include no groups specifically designed for women. The high spot in the Manosphere category is an antifeminist-themed group with $52 \%$ female participation, 
but this group is small (only 56 users total). Larger groups in this category with high participation rates by women include two groups decrying "false rape allegations" (45\% and 36\% female, 152 and 409 total users respectively) and one group protesting the "domestic violence industry" (34\%, 1627 total users).

In the Neo-Nazi category, the highest rates of female participation are found in two groups associated with The Creativity Movement, a Neo-Nazi religion [45], at $45 \%$ each. These groups are small, however, with only a few dozen members combined. The only group that has a sizable membership and a level of female participation above $35 \%$ is a group associated with the National Socialist Movement, a Neo-Nazi group with roots in the now-defunct American Nazi Party [46] (170 users total).

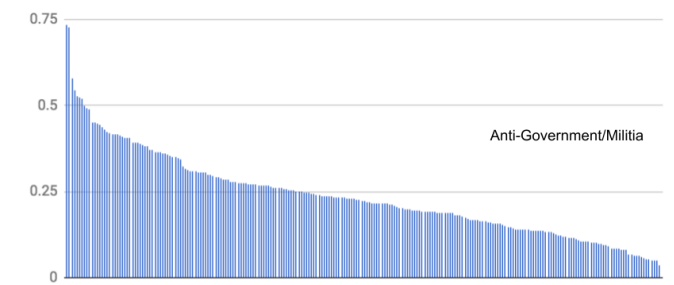

\section{Figure 3. Percent participation by women in Anti-Government/Militia groups}

3.3.4 A hybrid case. Anti-government "patriot" militias present an interesting case. Although we found no groups in this category specifically designed for women, Figure 3 shows there are eight groups with fairly high participation rates by women, at around 50\% or higher, including two with more than $70 \%$ women. What is it about these groups that is causing women to join? The reasons are unclear, but of the top 20 groups with the highest female participation rates in this category, 10 of them were associated with a nationwide organization known as the "Freedom Crew" run by team of activists called The Hiwaymen [47]. The user counts in these groups vary widely, between 11 and 963. Many of the groups are geographically focused, with the smaller ones indicating they are located in areas as small as one rural county. Activists in these groups attend rallies and watch Facebook Live videos starring the Hiwaymen leaders as "e-celebrities". Comments made during the videos appear to come from female fans.

The remaining groups in this category that attract female participants are associated with a variety of gender-neutral patriot/militia organizations including Oath Keepers, American Freedom Keepers, and an event series called MOAR (Mother of all Rallies). Recall that [5] indicated that $55 \%$ of Tea Party adherents were women, and the Tea Party was closely related to the militia movement [4]. Additional research should be conducted to help explain the appeal of these groups to women.

3.3.5. Summary of female group participation. To summarize, we observe a few patterns of gendered participation in radical right Facebook groups:

- Three ideologies - Proud Boys, White Nationalists, and Alt-Right - have created multiple groups on Facebook specifically for women. These wheat fields typically have more than $70 \%$ female membership, and a female enrollment rate that is much higher than the non-wheat fields. The AntiSemitic and Neo-Confederate ideologies also create wheat fields, but the groups are smaller (in the case of Anti-Semitic) and the participation rate differences are less dramatic (in the case of NeoConfederate).

- Four other ideologies - anti-Muslim, antiimmigrant, Manosphere, neo-Nazi - do not seem to have wheat fields for women. Across all four ideologies, there is only one group that specifically states it is designed for women, and that group only has $45 \%$ female membership. No group has higher than $67 \%$ female membership.

- The anti-government "patriot" militia groups are a hybrid case: a few groups are not designed for women in their messaging or naming, but are populated by a supermajority of women.

\subsection{Women in leadership roles}

Next, we turn our attention to the leadership roles within these Facebook groups. Do some ideologies promote women to leadership roles more than others? Do women serve as leaders in their own wheat fields?

3.4.1. Facebook group leadership roles. Facebook provides roles of "moderator" and "administrator" as leadership opportunities in its groups. Group administrators can change settings of the group and can appoint moderators and other administrators. Moderators can help the administrator by deleting posts, adding members, and other such tasks [48]. Groups can have unlimited numbers of moderators and administrators, but typically groups will have one or two of each, depending its size and activity level.

Table 6 (next page) shows the leadership roles assumed by women for each ideology. The final column in the table shows the difference between female membership rates and leadership rates across these ideologies. The figures range from six percentage points fewer female leaders than female members (White Power/White Nationalist), to ten percentage points more female leaders than members (Neo-Nazi).

What about the women-focused wheat fields? Are those groups led by women? Table 7 shows that the 
majority of leadership positions in the wheat fields are indeed occupied by women. However, it is important to note that there are only 13 wheat field groups in our data set (and a total of only 24 leadership positions among them) the vast majority of leadership by women is happening outside the wheat fields. There are 1,079 female leaders for 4,863 leadership positions $(22 \%$ female) across all 10 ideologies. A 22\% female leadership rate is lower than the $28 \%$ female overall membership rate we reported in Table 2, but the difference is within the $7.8 \%$ error rate for name resolution we showed in Table 3 .

Table 6. Female leadership by ideology, sorted by percent female leadership

\begin{tabular}{|l|r|r|r|}
\hline Ideology & $\begin{array}{r}\text { \% Fem } \\
\text { Overall }\end{array}$ & $\begin{array}{r}\text { \% Fem } \\
\text { Leaders }\end{array}$ & \multicolumn{1}{|c|}{ Difference } \\
\hline WN & $26 \%$ & $20 \%$ & $-6 \%$ \\
\hline PB & $10 \%$ & $6 \%$ & $-4 \%$ \\
\hline NC & $27 \%$ & $23 \%$ & $-3 \%$ \\
\hline AG & $23 \%$ & $24 \%$ & $0 \%$ \\
\hline AI & $41 \%$ & $42 \%$ & $1 \%$ \\
\hline MN & $10 \%$ & $11 \%$ & $1 \%$ \\
\hline AR & $12 \%$ & $16 \%$ & $4 \%$ \\
\hline AS & $22 \%$ & $28 \%$ & $6 \%$ \\
\hline AM & $28 \%$ & $35 \%$ & $7 \%$ \\
\hline NN & $15 \%$ & $26 \%$ & $10 \%$ \\
\hline
\end{tabular}

Table 7. Female leadership, wheat field groups

\begin{tabular}{|l|r|r|r|r|}
\hline Ideology & \multicolumn{1}{|c|}{$\begin{array}{c}\text { \# Wheat } \\
\text { fields }\end{array}$} & $\begin{array}{c}\text { \# Fem } \\
\text { leaders }\end{array}$ & $\begin{array}{c}\text { \# All } \\
\text { leaders }\end{array}$ & $\begin{array}{c}\text { \% Fem } \\
\text { Leaders }\end{array}$ \\
\hline PB & 2 & 3 & 3 & $100 \%$ \\
\hline WN & 5 & 8 & 8 & $100 \%$ \\
\hline AR & 4 & 5 & 7 & $71 \%$ \\
\hline AS & 1 & 1 & 1 & $100 \%$ \\
\hline NC & 1 & 3 & 5 & $60 \%$ \\
\hline
\end{tabular}

3.4.2. Summary of female leadership. To summarize, we observe the following patterns about gender and leadership in these groups on Facebook:

- Women participating in radical right groups on Facebook will join wheat fields if they are provided, and women do take on leadership roles within these wheat fields.

- Non-wheat field groups also attract some female participation and leadership. Women lead nonwheat field groups in some ideologies (Neo-Nazi, Anti-Muslim) more than in others (Proud Boys).

\subsection{Historical wheat fields}

Unfortunately, because all of the wheat field groups on Facebook are "Closed" to non-members, discussions that happen inside them were not observed. It is unknown how the women in those Facebook groups react to the existence of the group, other than the fact that they joined it. Thus, we turn to historical examples to broaden our understanding how the sequestration of women into similar groups has occurred. In what way do contemporary online wheat fields resemble women's groups of the "real world" past?

Historian Caroline Janney explores the role of Ladies' Memorial Associations (LMAs) directly following the Civil War in the United States. From 1865-1915, well-to-do southern white women banded together to create maintain cemeteries for Confederate soldiers [49]. The women of the LMAs were more effective than men at creating an emotional attachment to the "Lost Cause" of the Confederacy [50]. Other women's groups founded later, such as the United Daughters of the Confederacy (UDC), tapped into this same emotional well, creating publicity campaigns for the Lost Cause, such as adding material about "faithful slaves" and "state's rights" to children's textbooks and promoting the erection of a monument in Washington, D.C. dedicated to the "noble black mammy" [51]. By sheltering their activism beneath a non-threatening role as mourners and moral guardians of the home and family, Janney explains, women in these early wheat fields were participating in deeply political acts that laid a foundation for the enduring Lost Cause narrative that drives neo-Confederate nationalism - and we would add "tradwives" - even today.

The Ku Klux Klan terror organization also began in 1867 , and while white women were not permitted to join, they served as both its motivation and its enablers. Protection of white womanhood, especially against a perceived threat of sexual violence by black men, served as a powerful motivator and recruiting tool in the early Klan [52]. In her sympathetic history of the Klan, Susan Lawrence Davis describes Klanswomen so enamored of the mission of the Klan that they "took the clothes off their backs and the sheets off of their beds to make the ghostly regalia for the Ku Klux Klan." [53]

By the 1920 s, southern nationalism had spread well beyond the South and combined with anti-immigrant, anti-Semitic, racist sentiment throughout the United States to re-inspire a second - and much larger - wave of $\mathrm{Ku}$ Klux Klan membership. Kathleen Blee's scholarship on Klanswomen during this period describes how 500,000 white Protestant women turned their traditions of organizing church suppers and family reunions into vehicles for supporting bigotry and violence nationwide [54]. Importantly, in the middle of the suffrage movement, the Women's Ku Klux Klan (WKKK) was designed not to be an attendant ladies' auxiliary. Rather, the WKKK had separate leadership, a separate headquarters, and a distinct hierarchy from the men's group. Nonetheless, the men's group still referred to the women's group as an auxiliary, and described the women themselves as "helpmates" to the men. 
Regardless of occasional tension between the sexes, Blee explains that the presence of women, children, and even babies in the WKKK served to normalize the image of the Klan as a whole, and that the women used their personal networks to spread its ideology. Thus, we are not surprised that social networks are used for the same purpose in the $21^{\text {st }}$ century. The fact that we find women leading mixed-gender, radical right online groups is also not without precedent. Blee [6] describes many examples of pre-Internet Klanswomen and skinhead women tasked with recruitment and moderation of mixed-gender social spaces.

\section{Limitations and Future Work}

We have outlined the difficulties both in collecting Facebook data and dividing radical right groups into ideological categories in prior work [55]. The most significant of these concerns is that, despite our best efforts and expert panel consensus, it is possible that we missed some important groups, or we may have misclassified groups. Some groups were very hard to classify because they meet more than one definition (most racist groups are also Anti-Semitic, for example).

In terms of this gender-based study, we acknowledge the problems with using software to determine gender from a first name (see Section 3.1). We felt unsatisfied by a $7.8 \%$ error rate. In the future we would like to try different gender resolution packages, and we would like to understand the reasons for the higher rate of unknown names in some ideologies (see Section 3.2.1).

We also are under no illusions that the names being used by Facebook users are a true reflection of their gender identity. Despite Facebook's "real names" policy [56], many members of clandestine organizations such as radical right groups do not use their real names on Facebook or other social media. Facebook acknowledges that it has problems with "inauthentic" accounts, fake names, bots, and so on [57]. In addition, prior research [58] indicates that even if the accounts represent real people, deliberate gender swapping and gender obscuring can occur in online communities where hostility and trolling are commonplace.

Finally, page limits precluded a deeper discussion of leadership roles by women, especially in the non-wheat field groups. A follow-up qualitative study with interviews of women who lead or participate in these groups would be very interesting.

\section{Conclusions}

The purpose of this research was to gather data to help quantify and describe participation of women in extreme far-right political groups, a notoriously hard-to- measure demographic. In the social media age, many of these groups have presence on social media and are using networks like Facebook to recruit and plan events. We constructed a large list of radical right groups, downloaded their membership rosters using the Facebook API, and used gender resolution software to infer the gender of the individuals. We find that some ideologies have created specific communities for their female adherents, which are mockingly referred to as "wheat fields". Our data shows that women do join the wheat fields at much higher rates than they join nonwheat field groups. Leadership positions in wheat field groups are also predominantly held by women, but women also hold leadership positions in mixed-gender groups in some ideologies as well. Finally, we explore commonalities between female participation in the social networks of today's radical right and historical women's groups such as the LMAs and the WKKK. We find a long history of systematic marginalization and oppression of women on the one hand, versus a practical need to leverage women's networks and organizational abilities on the other hand.

\section{References}

[1] S. Peled, "Ladies' Night at the Alt-right: Meet the Women Trying to Soften the White Nationalist Movement", Haaretz, Nov. 25, 2017. https://haaretz.com/usnews/.premium-meet-the-women-trying-to-soften-thewhite-nationalist-movement-1.5462886

[2] Anti-Defamation League, "Have Hate, Will Travel: The Demographics of Unite the Right", Oct. 8, 2017. https:// adl.org/blog/have-hate-will-travel-the-demographics-ofunite-the-right

[3] P.S. Forscher \& N.S. Kteily. "A Psychological Profile of the Alt-Right", Aug. 9, 2016. 10.17605/OSF.IO/C9UVW

[4] D. Neiwert, Alt-America: The Rise of the Radical Right in the Age of Trump, Verso, London, 2017.

[5] Quinnipiac Poll, "Tea Party Could Hurt GOP In Congressional Races", Mar. 24, 2010, https://poll.qu.edu/ national/release-detail?ReleaseID $=1436$

[6] K.M. Blee, Inside Organized Racism: Women in the Hate Movement, U. of California Press, Berkeley, 2002.

[7] Southern Poverty Law Center, "The Alt-Right", https:// splcenter.org/fighting-hate/extremist-files/ideology/altright

[8] ADL, "From Alt Right to Alt Lite: Naming the Hate", https://adl.org/resources/back grounders/from-alt-rightto-alt-lite-naming-the-hate

[9] SPLC, "Active Patriot Groups in the US in 2016", 2016, https://splcenter.org/fighting-hate/intelligence-report /2017/active-patriot-groups-us-2016

[10] ADL, "The 'Patriot' movement", https://adl.org/ education/resources/glossary-terms/ patriot-movement

[11] ADL, "Defining Extremism: A Glossary of AntiGovernment Extremist Terms, Movements and Philosophies", https://adl.org/education/resources/ glossary-terms/defining-extremism-anti-government 
[12] SPLC, "Anti-Immigrant", https://splcenter.org/fightinghate/extremist-files/ ideology/anti-immigrant

[13] ADL, "Education resources on immigration, immigrants and anti-immigrant bias", https://adl.org/education/ resources/tools-and-strategies/education-resources-onimmigration-immigrants-and-anti

[14] SPLC, "Anti-Muslim", https://splcenter.org/fightinghate/extremist-files/ideology/anti-muslim

[15] ADL, "Anti-Muslim Bigotry", https://adl.org/education/ resources/backgrounders/anti-muslim-bigotry

[16] ADL, "Anti-Semitism", https://adl.org/anti-semitism

[17] SPLC, "Christian Identity", https://splcenter.org/fighting -hate/extremist-files/ideology/christian-identity

[18] ADL, "Christian Identity", https://adl.org/education/ resources/backgrounders/christian-identity

[19] SPLC. "Male Supremacy", https://splcenter.org/fighting -hate/extremist-files/ ideology/male-supremacy

[20] SPLC. "Misogyny: The Sites", https://splcenter.org/ fighting-hate/intelligence-report/ 2012/misogyny-sites

[21] SPLC, "Neo-Confederate", https://splcenter.org/fighting -hate/extremist-files/ideology/neo-confederate

[22] E. Hague, H. Beirich, \& E.H. Sebesta, NeoConfederacy: A Critical Introduction. U. of Texas Press, 2010.

[23] SPLC, "Neo-Nazi", https://splc enter.org/fightinghate/extremist-files/ideology/neo-nazi

[24] ADL, "Neo-Nazis", https://adl.org/education/resources /reports/state-of-white-supremacy

[25] SPLC, "General Hate", https://splcenter.org/fightinghate/extremist-files/ideology/general-hate

[26] SPLC, "New Alt-Right 'Fight Club' ready for street violence", https://splcenter.org/hatewatch/2017/04/25/ new-alt-right-fight-club-ready-street-violence

[27] SPLC, "Proud Boys", https://spl center.org/fightinghate/extremist-files/group/proud-boys

[28] SPLC, "White Nationalist", https://splcenter.org/fighting -hate/extremist-files/ideology/white-nationalist

[29] SPLC, "Ku Klux Klan", https:// splcenter.org/fightinghate/extremist-files/ideology/ku-klux-klan

[30] SPLC, "Neo-Volkisch", https:// splcenter.org/fightinghate/extremist-files/ideology/neo-volkisch

[31] Facebook, "What are the privacy settings for groups?", https://facebook.com/help/220336891328465

[32] Facebook, "How do I control who sees or joins my event?" https://facebook.com/help/208747122499067

[33] Facebook, "An update on our plans to restrict data access", Apr. 4, 2018. https://newsroom.fb.com/news/ 2018/04/restricting-data-access/

[34] Facebook, "Developer Platform Policy", https:// developers.facebook.com/policy

[35] Gender-Guesser. https://pypi.org/project/gender-guesser

[36] Genderize.io. https://store.genderize.io/

[37] P. Levy, "Alt-Right Movement Presents Its Vision for an All-White Society with Trump Paving the Way", Mother Jones, Sep. 9, 2016.

[38] E. Nelson, "The 'Alt-Right' Is A Hate Movement, And It's Scarier Than You Think", Huffington Post, Nov. 22, 2016. https://huffingtonpost.com/entry/alt-right-haterichard-spencer_us_5833242fe4b058ce7aac26fe
[39] Unicorn Riot, https://discordleaks.unicornriot.ninja

[40] G. McInnes, Proud Boys Manifesto. https://www.scribd. com/document/344624815/Proud-Boy-Manifesto

[41] SPLC, "Fraternal Order of Alt-Knights (FOAK)", https://splcenter.org/fighting-hate/extremist-files/group/ fraternal-order-alt-knights-foak

[42] G. McInnes, https://twitter.com/Gavin_McInnes/status/ 860612690112380928

[43] A. Kelly, "The Housewives of White Supremacy". New York Times, June 1, 2018. https://nytimes.com/2018/06/ 01/opinion/sunday/tradwives-women-alt-right.html

[44] M. Barkun, Religion and the Racist Right, University of North Carolina Press, Chapel Hill, NC, 1997.

[45] SPLC, "Creativity Movement", https://splcenter.org/fig hting-hate/extremist-files/group/creativity-movement-0

[46] SPLC, "National Socialist Movement", https://www.splcenter.org/fighting-hate/ extremistfiles/group/national-socialist-movement

[47] J. Green, "In Charlottesville, It Felt Like the Confederacy Was Trying to Rise Again". The Nation. Aug 15, 2017. https://thenation.com/article/incharlottesville-it-felt-like-the-confederacy-was-trying-torise-again/

[48] Facebook. "What is the difference between an admin and a moderator in a group?" https://facebook.com/help/ 901690736606156

[49] C.E. Janney, Burying the Dead but not the Past.: Ladies Memorial Associations and the Lose Cause. U. North Carolina Press, 2008.

[50] W.F. Brundage, "Women's Hand and Heart and Deathless Love", In C. Mills \& P.H. Simpson, (Eds.), Monuments to the Lost Cause: Women, Art, and the Landscapes of Southern Memory, U. of Tennessee Press, Knoxville, 2003.

[51] M. McElya, "Commemorating the Color Line", In C. Mills \& P.H. Simpson, (Eds.), Monuments to the Lost Cause: Women, Art, and the Landscapes of Southern Memory, U. of Tennessee Press, Knoxville, 2003.

[52] K.J. Baker, Gospel According to the Klan: The KKK's Appeal to Protestant America, 1915-1930, U. Press of Kansas, Lawrence, KS, 2011.

[53] S.L. Davis. Authentic History Ku Klux Klan 2865-1877, American Library Service, New York, 1924.

[54] K.M. Blee, Women of the Klan: Racism and Gender in the 1920s, U. of California Press, Los Angeles, 1991.

[55] M. Squire, "Network Analysis of Anti-Muslim Groups on Facebook", In Proc. $10^{\text {th }}$ Int. Conf. on Social Informatics, St. Petersburg Russia, 26 Sep. 2018.

[56] Facebook, "What names are allowed on Facebook?" https://facebook.com/help/112146705538576

[57] N. Fandos and K. Roose, "Facebook identifies an active political influence campaign using fake accounts," New York Times, July 31, 2018. https://nytimes.com/2018/07/ 31/us/politics/facebook-political-campaignmidterms.html

[58] B. Vasilescu, A. Capiluppi, \& A. Serebrenik, "Gender, representation and online participation: A quantitative study", In Proc. 4th Int. Conf. on Social Informatics, Lausanne, Switzerland, 14-16 Dec. 2012. 